\title{
Serious and Long-Term Adverse Events Associated with the Therapeutic and Cosmetic Use of Botulinum Toxin
}

\author{
Eugenia Yiannakopoulou \\ Faculty of Health and Caring Professions, Technological Educational Institute of Athens, Athens, Greece
}

\section{Key Words}

Botulinum toxin - Safety · Adverse events - Therapeutic use . Cosmetic use $\cdot$ Systematic review

\begin{abstract}
Although botulinum toxin is generally considered safe, its widespread use and the constantly expanded indications raise safety issues. This study aimed to review the serious and long-term adverse events associated with the therapeutic and cosmetic use of botulinum toxin. Serious adverse events included dysphagia, respiratory compromise, generalized muscle weakness, marked bilateral ptosis, pseudoaneurysm of the frontal branch of the temporal artery, necrotizing fasciitis, sarcoidal granuloma, Fournier gangrene, and cervical kyphosis. Death was attributed to botulism or anaphylactic shock. In conclusion, botulinum toxin may cause serious adverse events, which are more common after its therapeutic use, but can also be noticed after its cosmetic use. Thorough knowledge of the anatomy of the treated muscles and of the pharmacology of the drug is imperative to avoid serious adverse events.

(c) 2015 S. Karger AG, Basel
\end{abstract}

\section{Introduction}

Botulinum toxins are among the most toxic poisons known to humans, with a lethal dose of approximately 1 ng per kilogram body weight. There are seven serologically distinct botulinum toxins. Botulinum toxin $\mathrm{A}$ is the most potent serotype, with a toxicity one million-fold higher than cobra toxin and far higher than cyanide [1].

The therapeutic use of botulinum toxin was introduced about two centuries ago, when Justinus Andreas Christian Kerner recognized the effect of botulinum toxin on skeletal muscles and the parasympathetic function. Nowadays, the indications of botulinum toxin are constantly expanding. In 1979, botulinum toxin was approved for the treatment of strabismus, while, almost two decades ago, the therapeutic use of botulinum toxin for the treatment of hemifacial spasm, strabismus, and blepharospasm was introduced in clinical practice. The National Institutes of Health Consensus Conference in 1990 included botulinum toxin as safe and effective therapy for the treatment of adductor spasmodic dysphonia, oromandibular dystonia, and cervical dystonia. In the meantime, botulinum

\section{KARGER 125}

E-Mail karger@karger.com www.karger.com/pha (c) 2015 S. Karger AG, Base

0031-7012/15/0952-0065\$39.50/0
Eugenia Yiannakopoulou

Eleutheriou Benizelou 106 GR-17676 Kallithea (Greece)

E-Mail nyiannak@teiath.gr 
toxin was approved for the treatment of achalasia and primary axillary hyperhidrosis. Furthermore, since the approval of botulinum toxin type A for glabellar frown lines by the US Food and Drug Administration (FDA) in 2002, injections of botulinum toxin type A have become the most common cosmetic procedure. The treatment of facial lines other than glabellar wrinkles is considered an off-label use. Other off-label uses of botulinum toxin include Meige's syndrome, sphincter dysfunction, and migraine headaches, as well as tremor disorders, juvenile cerebral palsy, and other spasticity disorders [2].

Although botulinum toxin is generally considered safe, its widespread use and the constantly expanded indications raise safety issues. This paper aimed to review the serious and long-term adverse events of the therapeutic and cosmetic use of botulinum toxin.

\section{Pharmacovigilance}

Most data come from spontaneous reporting systems, retrospective studies, and case reports. In February 2008 and April 2009, the FDA published an early communication regarding botulinum toxin type $\mathrm{A}$ and botulinum toxin type $\mathrm{B}$, informing physicians that these drugs have been associated with systemic adverse reactions including respiratory compromise and death resembling those seen with botulism, in which botulinum toxin spreads to the body beyond the injection site [3]. In 2005, the FDA raised safety issues of botulinum toxin in a published analysis of adverse events covering the period from 1989 to 2003 [4]. According to that publication, there were 407 adverse event reports related to the therapeutic use of botulinum toxin (median dose of 100 units), 217 of which met the FDA's definition of serious adverse events. It should be emphasized that in the majority of these patients, significant comorbidities could have contributed to the fatal outcome. There were also 36 reports related to the cosmetic use, with the majority concerning dysphagia. Thirty of them were characterized as possible complications of botulinum toxin, while the other 6 did not display a pattern, suggesting a causal relationship between the adverse event and botulinum toxin type A.

In 2008, the National Consumer Advisory Group analyzed FDA data that included 658 adverse events, of which 180 were aspiration, dysphagia or pneumonia. There were 16 deaths, 4 of which occurred in children under the age of 18 [5].

The Danish Medicines Agency has received 9 reports of serious adverse events related to the therapeutic use of botulinum toxin, including dyspnea with speech and eating disturbance, general muscle weakness (3 cases), muscle atrophy, spasms and neck pain, significant loss of strength in the arms/hands with hand drop, muscle weakness in the arms, and weakening of respiratory muscles necessitating respiratory treatment. The therapeutic indications in the above cases were overactive bladder ( 2 cases), dystonia of the shoulder muscles, cervical dystonia (2 cases), urinary incontinence, neurological bladder, and undisclosed (3 cases) [6].

The serious adverse events identified in case reports varied from idiosyncratic adverse reactions like anaphylactic shock to dose-dependent adverse reactions like cervical kyphosis and botulism [7-38]. They were attributed to various types and preparations of botulinum toxin. However, in most cases, a causality with botulinum toxin was not established. Serious adverse events related to the cosmetic use of botulinum toxin include thyroid eye disease in a patient with Graves hyperthyroidism, sarcoidal granuloma, pseudoaneurysm of the frontal branch of the superior temporal artery, and severe respiratory failure [8-11]. In addition, botulism-like generalized weakness has been reported in a patient treated for axillary and palmar hyperhidrosis [12]. Serious adverse events related to the therapeutic use of botulinum toxin include severe velopharyngeal insufficiency, brachial plexopathy, remote muscle weakness, botulism-like generalized muscle weakness, necrotizing fasciitis, crisis of myasthenia, generalized paralysis, marked bilateral blepharoptosis, impairment of speech and chewing, Guillain-Barré syndrome, severe dysphagia, iatrogenic botulism, generalized skin rash, aspiration pneumonia, unilateral facial madarosis and alopecia, and palatal palsy [13-38]. It is interesting that one of the patients presented with generalized weakness 5 years after continued use of botulinum toxin [19]. Furthermore, death due to anaphylactic shock has been reported in a patient treated with a botulinum toxin-lidocaine mixture for chronic neck and back pain, cervical kyphosis in a patient treated for chronic cervical pain, and Fournier gangrene in a diabetic patient treated for anal fissure [36-38].

\section{Epidemiological Studies}

A limited number of epidemiological studies have been published. The first one investigated the effect of distant diffusion of botulinum toxin in a cohort of 187 patients that received 266 botulinum toxin injections for spasticity treatment. Patients were followed up for 1 month after the injection. Five patients presented with adverse events attributed to systematic diffusion of botu-
Yiannakopoulou 
linum toxin A. Two of these adverse events were severe, since the patients complained of diffuse muscle weakening with inability to walk. One of them was hospitalized for a prolonged time [39].

The other epidemiological study reported symptoms of mild systemic botulism (fatigue, ptosis, diplopia, and dysarthria) in a 13-year-old child suffering from cerebral palsy, who received $23 \mathrm{U} / \mathrm{kg}$ of Botox into the lower extremity musculature. She had no dysphagia or respiratory compromise, and the symptoms resolved within 6 weeks [40]. In a retrospective study of 758 patients suffering from cerebral palsy treated with Dysport, the authors reported 2 cases of mild ptosis and 6 cases of generalized weakness [41].

Few data on the long-term adverse events of botulinum toxin were identified. Most of them concern the therapeutic use of botulinum toxin. Long-term safety data indicate that toxic effects of botulinum toxin can appear at the 10th or 11th injection, after prior uncomplicated injections. The longest follow-up study of $45 \mathrm{pa}-$ tients continuously treated with botulinum toxin for 12 years identified 20 adverse events in 16 patients including dysphagia, ptosis, neck weakness, nausea/vomiting, blurred vision, marked weakness, chewing difficulties, hoarseness, edema, dysarthria, palpitations, and general weakness [42].

Kessler et al. [43] analyzed data from 303 cervical dystonia patients who received at least 6 botulinum toxin injections within a period of at least 2 years. According to the authors, only $25 \%$ of the patients did not experience any side effects during the course of the treatment. The most frequent adverse event was dysphagia, which occurred on average 9.7 days after the injection and lasted on average 3.5 weeks. Dysphagia was severe in 24 patients, but hospitalization or insertion of a nasogastric tube was not necessary [43].

Resistance to botulinum toxin due to the development of antibodies to the toxin has also been reported as longterm adverse event of the therapeutic use of botulinum toxin. According to a case report, one patient experienced madarosis and facial alopecia after 18 months of treatment with botulinum toxin for oromandibular dystonia [28]. No data were identified for adverse events appearing a long time after cessation of exposure to the drug.

Concerning repeated injections of botulinum toxin for cosmetic use, data were quite scarce. A retrospective study of 4,103 injections for the treatment of lines of the upper face for 943 patients was identified. The patients received a minimum of 3 consecutive documented treatment cycles. The authors concluded that there was no ev- idence of cumulative adverse events. On the contrary, the event rate decreased in later treatment cycles [44]. In a case report of a patient who regularly received botulinum toxin type A for frontal and glabellar lines for a period of 13 years, no adverse events were reported [45].

\section{Discussion}

Botulinum neurotoxins represent some of the most toxic naturally occurring substances. Their mechanism of action is based on the inhibition of acetylcholine release at the neuromuscular junction of striated muscles, thus resulting in chemical denervation and muscle paralysis. Given that the indications of botulinum toxin are constantly expanding, knowledge of the serious adverse events and long-term safety of botulinum toxin is imperative.

Although randomized controlled trials could contribute data on the safety of botulinum toxin, they actually do not report serious or long-term adverse events of botulinum toxin. Most serious adverse events of botulinum toxin come from spontaneous reporting systems and case reports $[46,47]$. However, spontaneous reporting systems cannot be used to determine the incidence of adverse events, as adverse events are underreported and neither patient exposure nor the amount of time the drug was in the market has been taken into consideration. Yet, an assessment of causality is difficult in the context of spontaneous reporting systems. However, case series and case reports are a cornerstone of drug safety research [48]. Moreover, statistical modelling suggests that more than 1-3 spontaneously reported cases of rare adverse events are very unlikely to be coincidental [49]. Yet, it is difficult to estimate the incidence of serious adverse events due to significant underreporting worldwide. Furthermore, there are no studies of the prevalence of the use of botulinum toxin. However, statistical data from the American Society for Aesthetic and Plastic Surgery indicate that $2,557,068$ procedures were performed in 2009 [50].

Pharmacovigilance data and case reports imply that botulinum toxin may be associated with serious adverse events such as botulism, generalized paralysis, dysphagia, respiratory depression, and even death. These adverse events are attributed either to the mode of action of botulinum toxin, i.e. muscle paralysis of the wrong muscle, or to the chemical structure of the drug (protein) resulting in hypersensitivity reactions. Serious adverse events may be dose dependent and attributed to local diffusion of botulinum toxin in adjacent areas, such as neck extensor 
myopathy and dysphagia [51]. Indeed, diffusion of botulinum toxin in the injected muscle and adjacent muscles has been well documented [52], even if these muscles are separated by fasciae. Diffusion of botulinum toxin to contralateral muscles has also been reported. Animal studies have shown that botulinum toxin can spread to a distance of 30-45 $\mathrm{mm}$ from the injection site. However, generalized diffusion of botulinum toxin is possible especially after long-term therapeutic or cosmetic use. The effects of generalized diffusion are not well studied. The mechanism responsible for the generalized diffusion of botulinum toxin is not known. Proposed hypotheses concern either a systemic spread or a retrograde axonal spread of toxin. Systemic toxin spread can lead to adverse events suggesting botulism, including muscle weakness or paralysis, dysarthria, dysphonia, dysphagia, and respiratory arrest. These adverse events may be fatal if left untreated. Additionally, experimental studies in rodents have shown that botulinum toxin receptors exist in the central nervous system and a small amount of botulinum toxin crosses the blood-brain barrier [53]. This raises the possibility that botulinum toxin is transported retrogradely, similar to tetanus toxin, and may cause centrally mediated side effects.

An interesting issue is how we could avoid the adverse events of botulinum toxin. First of all, physicians administering botulinum toxin should be familiar with the anatomy of the muscles involved and with any alterations to the anatomy due to prior surgical procedures. Proper storage of the product, selection of the correct dose, and proper reconstitution and administration techniques should be applied. Several warnings should be taken into account. Patients with diseases of the neuromuscular junction such as myasthenia gravis and Lambert-Eaton syndrome are particularly susceptible to adverse events of botulinum toxin. Patients with anterior horn disorders are also reported to have a hypersensitivity to botulinum toxin. In general, botulinum toxin is contraindicated in patients with a known hypersensitivity to the components of the formulation or with disorders of the neuromuscular junction, in coadministration with aminoglycoside antibiotics or streptomycin, when there is a bleeding disorder or anticoagulant therapy, and during pregnancy. Yet, it is recommended that patients with suspected latent subclinical neuromuscular junction disorder should be systemically tested prior to botulinum toxin administration and then be treated with caution even if botulinum toxin is to be used in small doses.

Further research is needed on the proper dosage of botulinum toxin. For example, although the maximum dose per treatment session for glabellar lines is $20 \mathrm{U}$ for all sessions combined, the upper dosing limit for the therapeutic use of botulinum toxin has not been specified. Studies in adults suggest that $3 \mathrm{U}$ of Dysport is equivalent to $1 \mathrm{U}$ of Botox. There are no data to provide dosing guidance for the botulinum toxin B formulation Myobloc. In general, there is a great variation in the total doses of botulinum toxin administered across studies, as well as in the dilution, the number of muscles injected, and whether dosing should be based on fat-free mass or on body weight.

\section{Conclusion}

Adverse events are more common after the therapeutic use of botulinum toxin, but can also be noticed after its cosmetic use. There are not enough data on the longterm safety of this drug, especially when used for cosmetic reasons. Thorough knowledge of the anatomy of the treated muscles and of the pharmacology of the drug is imperative to avoid serious adverse events.

\section{Disclosure Statement}

The author reports no conflicts of interest.

References strange case of the botulinum neurotoxin chemistry and biology to modulate the most deadly poison. Angew Chem Int Ed Engl 2008;47:8360-8379.

2 Klein AW: Contraindications and complications with the use of botulinum toxin. Clin Dermatol 2004;22:66-75.

-3 Naumann M, Jancovic J: Safety of botulinum toxin type A: a systematic review and metaanalysis. Curr Med Res Opin 2004;20:981990

4 Anonymous FDA News Release: FDA requires box warning for all botulinum toxin products. http://www.fda.gov/Newsevents/ Newsroom/Press Announcements / ucm 149574.htm (accessed October 10, 2010).

5 Cote TR, Mohan AK, Polder JA, et al: Botulinum toxin type A injections: adverse events reported to the US Food and Drug Administration in therapeutic and cosmetic cases. J Am Acad Dermatol 2005;53:407-415.

6 Public Citizen: Stricter warnings needed for Botox, Myobloc injections. http://www.citizen.org/pressroom/release.cfm?ID=2593 (accessed November 26, 2009).
Yiannakopoulou 
7 Adverse events to botulinum toxin (Botox, 22 Burguera JA, Villaroya T, Lopez Alemany T: Dysport, Dystabel, Neurobloc) - an update. http://www.dkma.dk (accessed November 26, 2009).

8 Ahbib S, Lachapelle JM, Marot L: Sarcoidal granulomas following injections of botulinum toxin A (Botox) for corrections of wrinkles. Ann Dermatol Venereol 2006;133:4345.

9 Harrison A, Erickson J: Thyroid eye disease presenting after cosmetic botulinum toxin injections Ophtal Plast Reconstr Surg 2006;22: 397-398.

10 Prado A, Fuentes P, Guerra C, et al: Pseudoaneurysm of the frontal branch of the superficial temporal artery: an unusual complication after the injection of Botox. Plast Reconstr Surg 2007;119:2334-2335.

11 Nong LB, He WQ, Xu YH, et al: Severe respiratory failure after injection of botulinum toxin: case report and review of the literature (in Chinese). Zhonghua Jie He He Hu Xi Za Zhi 2008;31:369-371.

12 Tugnoli R, Eleopra R, Quatrale R, et al: Botulism-like syndrome after botulinum toxin type A injections for focal hyperhidrosis. Br J Dermatol 2002;147:808-809.

13 Saeed SR, Brooks GB: The use of clostridium botulinum toxin in palatal myoclonus. A preliminary report. J Laryngol Otol 1993;107: 208-210.

14 Sheean GL, Murray NM, Marshden CD: Pain and remote weakness in limbs injected with botulinum toxin A for writer's cramp. Lancet 1995;346:154-156.

- 15 Sampaio C, Castro Caldas A, Sales Luis MA, et al: Brachial plexopathy after botulinum toxin administration for cervical dystonia. J Neurol Neurosurg Psychiatry 1993;56:220.

$\checkmark 16$ Mezaki T, Kaji R, Kohara N, et al: Development of general weakness in a patient with amyotrophic lateral sclerosis after focal botulinum toxin injection. Neurology 1996;46: 845-846.

17 Latimer PR, Hodgkins PR, Vakalis AN, et al: Necrotizing fasciitis as a complication of botulinum toxin injection. Eye (Lond) 1998;12: 51-53.

18 Borodic G: Myasthenic crisis after botulinum toxin. Lancet 1998;352:1832.

19 Bakheit AM, Ward CD, McLellan DL: Generalised botulism-like syndrome after intramuscular toxin type A: a report of two cases. J Neurol Neurosurg Psychiatry 1997;62:198.

20 Bhattia KP, Munchau A, Thompson PD, et al: Generalized muscle weakness after botulinum toxin injections for dystonia: report of three cases. J Neurol Neurosurg Psychiatry 1999;67:90-93.

-21 Muller-Vahl KR, Kolbe H, Egensperger R, et al: Mitochondriopathy, blepharospasm and treatment with botulinum toxin. Muscle Nerve 2000;23:647-648. Polyradiculoneuritis after botulinum toxin therapy for cervical dystonia. Clin Neuropharmacol 2000;23:226-228.

23 Thobois S, Broussole E, Toureille L, et al: Severe dysphagia after botulinum toxin injection for cervical dystonia in multiple system atrophy. Mov Disord 2001;16:764-765.

24 Beseler-Soto B, Sánchez-Palomares M, Santos-Serrano L, et al: Iatrogenic botulism: a complication to be taken into account in the treatment of child spacticity. Rev Neurol 2003;37:444-446.

25 Onoue H, Matsunobu A, Nagaishi A, et al: A case report of acute polyradiculoneuritis developing after multiple injections of botulinum toxin for cervical dystonia (in Japanese) Rinsho Sinseighaku 2004;44:20-24.

26 Mezaki T, Sakai R: Botulinum toxin and skin rash reaction. Mov Disord 2005;20:770.

27 Gioltzoglou T, Cordivari C, Lee PJ, et al: Problems with botulinum toxin treatment at mitochondrial cytopathy: case report and review of the literature. J Neurol Neurosurg Psychiatry 2005;76:1594-1596.

28 Kowing D: Madarosis and facial alopecia presumed secondary to botulinum toxin A injections. Optom Vis Sci 2005;82:579-582.

29 Duffey P, Brown C: Iatrogenic botulism in an amateur weight lifter. Mov Disord 2006;21: 1056.

30 Rossi RP, Strax TE, Di Rocco A: Severe dysphagia after botulinum toxin $B$ injection to the lower limbs and lumbar paraspinal muscles. Am J Phys Med Rehabil 2006;85:10111013.

31 Crowner B, Brustrom J, Racette B: Iatrogenic botulism due to therapautic botulin toxin $\mathrm{A}$ injection in a paediatric patient. Clin Neuropharmacol 2007;30:310-313.

32 Pal PK, Lakshmi PS, Nirmala M: Efficacy and complication of botulinum toxin injection in palatal myoclonus: experience from a patient. Mov Disord 2007;22:1484-1486.

33 Howell K, Selber P, Graham K, et al: Botulinum neurotoxin $A$ : an unusual systemic effect. J Paediatr Child Health 2007;43:510512.

34 Partikian A, Mitchell WG: Iatrogenic botulism in a child with spastic quadriparesis. J Child Neurol 2007;22:1235-1237.

35 Meijer JW, van Kuijk AA, Geurts AC, et al: Acute deterioration of bulbar function after botulinum toxin treatment for sialorrhea in amyotrophic lateral sclerosis. Am J Phys Med Rehabil 2008;87:321-324.

36 Li M, Goldberger BA, Hopkins C: Fatal case of Botox-related anaphylaxis? J Forensic Sci 2005;50:169-172.

37 Hogan K, Manning EL, Glaser JA: Progressive cervical kyphosis associated with botulinum toxin injection. South Med J 2006;99:888891.
38 Mallo-González N, López-Rodríguez R, Fentes DP, et al: Fournier's gangrene following botulinum toxin injection. Scand J Urol Nephrol 2008;42:301-303.

39 Roche N, Schnitzer A, Genet F, et al: Undesirable distant effects following botulinum toxin type A injection. Clin Neuropharmacol 2008; 31:272-280.

40 Goldstein EM: Safety of high-dose botulinum toxin type A therapy for the treatment of pediatric spasticity. J Child Neurol 2006;21:189192.

41 Bakheit AM, Severa S, Cosgrove A, et al: Safety profile and efficacy of botulinum toxin A (Dysport) in children with muscle spasticity. Dev Med Child Neurol 2001;43:234-238.

42 Mejia NI, Vuong KD, Jankovic J: Long-term botulinum toxin efficacy, safety, and immunogenicity. Mov Disord 2005;20:592-597.

43 Kessler KR, Skutta M, Benecke R: Long-term treatment of cervical dystonia with botulinum toxin A: efficacy, safety, and antibody frequency. German Dystonia Study Group. J Neurol 1999;246:265-274.

44 Rzany B, Dill Miller D, Grablowitz D, et al: Repeated botulinum toxin A injections for the treatment of lines in the upper face: a retrospective study of 4,103 treatments in 945 patients. Dermatol Surg 2007;33:S18-S25.

45 Binder WJ: Long term effects of botulinum toxin type A (Botox) on facial lines: a comparison in identical twins. Arch Facial Plast Surg 2006;8:426-431.

46 Yiannakopoulou E, Damianou C, Bamia C, et al: Adequacy of safety data reporting in randomized clinical trials comparing coxibs with non-selective NSAIDs. Epitheor Klin Farmakol Farmakokinet 2005;23:42-43.

47 Begaud P, Moride Y, Tubert Bitter P, et al: False positives in spontaneous reporting: should we worry about them? Br J Clin Pharmacol 1994;38:401-404.

48 Abou Chakra CN, Pariente A, Pinet M, et al: Case series in drug safety: a review to determine characteristics and quality. Drug Saf 2010;33:1081-1088.

49 Fishman P: Clinical uses of botulinum toxin. Adv Stud Med 2005;5:176-182.

50 Cosmetic Plastic Surgery Research: 2009 News Release. http://www.cosmeticplasticsurgerystatistics.com (accessed May 15, 2011).

51 Eleopra R, Tunogli V, Canatti L, et al: Botulinum toxin treatment in the facial muscles in humans: evidence of an action in untreated near muscles by peripheral local diffusion. Neurology 1996;46:1158-1160.

52 Yaraskavitch M, Leonard T, Herzog W: Botox produces functional weakness in non-injected muscles adjacent to the target muscle. J Biomech 2008;41:897-902.

53 Curra A, Berardelli A: Do the unintended actions of botulinum toxin at distant sites have clinical implications? Neurology 2009;72: 1095-1099. 